\title{
STUDENT PERCEPTION OF SCIENCE AS INFLUENCED BY SPARK SCIENCE LEARNING SYSTEM (SSLS)
}

\author{
Maribel D. Ganeb, Darryl Roy T. Montebon
}

\begin{abstract}
The present research explores the perception of students on their use of the SPARK Science Learning System device and sensors in their science classes as they study the $\mathrm{K}$ to 12 science modules in the Philippines. Two groups of students were assigned to be the experimental and the control group of the study. The experimental group was exposed to the SPARK Science Learning System and the other group was not. To determine the perceptions of both groups on their science classes, the instrument, iKnow My Class Survey was utilized. Upon analysis, it has been found out that the difference in the pre-test mean and the post-test mean on the survey conducted was statistically significant with a p-value of less than 0.05 (pvalue $=0.019<0.05)$. Thus, it can be concluded that the use of SPARK Science Learning System incurred better perception of science classes among students.
\end{abstract}

Keywords: SPARK Learning System, ICT in the classroom, Perception

\section{Introduction}

A significant change was implemented in the Philippine education system-the K to 12 Program. The Enhanced Basic Education Curriculum or the K12 Curriculum was carried out by virtue of Republic Act (RA) 10533 in 2012. In particular, the Science program under the $\mathrm{K}$ to 12 experienced major reforms: decongestion of topics, inquiry based instruction, contextualization of lessons, and the spiral progression of competencies. All of the described reforms are to develop as scientifically literate citizen.

The change in the curriculum influenced different perspectives among its stakeholders. First, students perceived the K to 12 program to help them become holistic individuals (Montebon, 2014). Second, parents view the $\mathrm{K}$ to 12 curriculum to have good and bad impacts to their way of living (Cabansag, 2014). Lastly, teachers see the curriculum to help students for the challenges of the $21^{\text {st }}$ Century (Tuga \& Montebon, 2017).

Though the change in curriculum influenced different perceptions in the $\mathrm{K}$ to 12 program, the present research introduces a method how to help students survive in the new curriculum - through the use of SPARK Learning System (SSLS) in science. Using SSLS as technology in science is hoped to aid science teaching and learning; since, technology help students develop positive perceptions towards the discipline. Studies also reveal that the nature of the learners nowadays is inclined towards technology, thus using technology in the classroom helps them achieve better (Morales, 2014; Clark, 2010; Auditor \& Roleda, 2014).

The findings of this study could be an indicator to educators to continuously utilize SSLS as an instructional tool in science. The interest of the learners may lead to positive outcome wherein they 
view and find science as an enjoyable subject; thus, promoting student motivation. Results of the present research could also inform and encourage teachers to maximize the use of the SPARK in their lessons.

\section{The Related Literature}

\section{Curriculum Change in the Philippines}

According to the DepEd K to 12 Curriculum Guide (2013) the science education aims to develop scientific literacy among learners that will prepare them to become informed and be participative citizens who are able to make sound judgments on matters regarding the applications of scientific knowledge that may have social, health, or environmental impacts. The science curriculum recognizes the place of science and technology in everyday human affairs. It integrates science and technology in the social, economic, personal and ethical aspects of life. Further, one of the aims of the new K12 curriculum is to prepare students to become globally competitive individuals and attain the optimum scientific and technological literacy.

The science curriculum promotes a strong link between science and technology including indigenous technology; thus, preserving our country's cultural heritage. The $\mathrm{K}$ to 12 science curriculum will provide learners with a repertoire of competencies important in the world of work and in a knowledgebased society. It envisions the development of scientifically, technologically, and environmentally literate and productive members of society who are critical problem solvers, responsible stewards of nature, innovative and creative citizens, informed decision makers, and effective communicators.

As a whole, the $\mathrm{K}$ to 12 Science Curriculum is learner-centered and inquiry-based, emphasizing the use of evidence in constructing explanations. Concepts and skills in life sciences, physics, chemistry, and earth sciences are presented with increasing levels of complexity from one grade level to another in spiral progression, thus paving the way to a deeper understanding of core concepts. The integration across science topics and other disciplines will lead to a meaningful understanding of concepts and its application to real-life situations primarily aims to help students understand scientific knowledge and to develop the ability of the scientific inquiry skills. Feedback on the implementation of this newly adopted curriculum may take time from the period of its implementation because it will take two more years to assess the performance level of pioneer students in National Achievement Test under the newly enhanced science curriculum.

\section{Student Perception of Science and their Performance in Class}

The main role of perception in learning is to speed up the learning process and recall. Perception involves the use of identification and sensory information of a subject. Exposure to stimulus develops the interest and conscious knowledge of a person which enables better understanding and learning of the person about a specific subject (Kumar \& Sampath, 2010).

Some students perceive that their teachers' instructional practices are oriented towards helping them learn but lack of inquiry-oriented activities and support or encouragement for self-directed and effortful learning (Bernardo, et.al, 2008). Without positive attitudes and perceptions, students have little chance of learning proficiently (Marzano, 2006). Learners' perception in science in general plays an important role to learners' achievement. The students' perception of learning is correlated is much higher with student ratings of instruction and did significant gain in their pre-and posttest scores (Centra \& Gaubatz, 2005). Moreover, the learners' negative perception in science can be a hindrance in uplifting the interest of students in learning science (Hancer \& Tuzemen 2008; Valdez, 2005; Yakar, $2005 \&$ Salgut, 2007). If students develop or possess a better perception towards the subject, they may always look forward to learn more about the subject (Fonseco \& Conboy, 2006; Aurentz, Kerns \& Shibley, 2011; Centra \& Gaubatz, 2005).

Researchers in the developed countries like the United States have focused on students' perceptions of science classes to try to understand some of the problems in the science educational system in their countries (Bernardo, et.al, 2008). Educators must prepare for a technology-rich future and keep up 
with change by adopting effective strategies that infuse lessons with appropriate technologies (Valdez, 2005).

Kardash and Wallace (2001) made an instrument to assess the perceptions of students and obtain quantitative data on student perceptions. Their study revealed perceptions related to the problems of teaching in science classes (1) pedagogical strategies, (2) faculty interest in teaching, (3) student interest and perceived competence in science, (4) passive learning, (5) grades as feedback, and (6) laboratory experiences. Women differed significantly from men on the pedagogical strategies, passive learning, grades as feedback, and laboratory experiences factors. Correlational analyses and evidence from distinct groups supported the survey's construct validity. Students reported room for improvement of the science faculty's pedagogical practices. From the students' perspective, how information is taught appears to be the concern to what knowledge is being learned (Psych Info Database Record, 2012).

Bevins and Brodie (2005) conducted a study in England on secondary school students' perceptions of science and engineering. They found out that students do not recognize the specific identities and importance of science regarding its role in society as much as it does with politics. Students suggested that they would benefit if teachers are able to utilize their expertise in the classroom at a time where the experts' particular specialist knowledge would greatly enhance the concepts being taught: students' perceptions towards classroom science. Responses from interviews indicate that students view physics as a difficult and complex subject. The students also suggest that topics such as forces have little relevance to their life experiences. School-based educational experiences have a strong influence on students' decision making and career choices. Students perceive physics as 'too hard' and not relevant to them and it is unlikely they will consider further study and career options related to this subject. Biology, on the other hand, is viewed as 'easier' and 'more meaningful'. Students suggest that the application of concepts from biology is transparent and recognizable to them in everyday situations while physics and chemistry have few immediate linkages with their everyday lives. It highlights students' apparent interest in science but lacks enthusiasm for school science education that pays little or no attention to science related issues that students encounter throughout their daily lives. Furthermore, participating students highlight the impact of restricted involvement in practical/hands on sessions in classroom science. The science curriculum is heavily content loaded which reduces teachers' opportunities for engaging students in practical sessions.

In the Philippines, Bernardo, et.al (2008) conducted a study which was a modified version of The Perception of Science Classes Survey by Kardash and Wallace (2001) entitled "Students' Perceptions of Science Classes in the Philippines (PSCS)" and surveyed 7,885 grade school and high school students in different provinces in the Philippines regarding their perceptions of their science classes. They developed a survey questionnaire based on the PSCS to study perceptions of Filipino students regarding their science classes. The results suggest that students perceive that their teachers' instructional practices are oriented towards helping them learn but that these practices do not involve enough of inquiry-oriented activities and do not provide enough support or encouragement for selfdirected and effortful learning.

Auditor and Roleda (2014), recently conducted a study on the impact of WebQuest on students' critical thinking, performance and perception in basic Physics. Researchers' study determined the relationship between students' content-knowledge acquisition and perception. They employed both descriptive and inferential data analysis procedures. On students' perceptions, statistical analysis showed that students responded positively on the use of Web Quest model in terms of collaboration, creativity, motivation, and knowledge enhancement but were not in time management. They found out there was negligible correlation between students' academic performance and perceptions. Generally, they found out that students viewed Web Quest favorably irrespective of their ability to learn and it suggests that WebQuest model can be a useful tool for student learning.

\section{Integration of computer assisted instruction in science}

It is well-established by researches that integrating technology into the curriculum and instruction will bring about significant student achievement and deep understanding of concepts (Clark, 2010; 
Morales, 2014; Auditor \& Roleda, 2014). However, technology has to be integrated meaningfully into the curriculum and instruction for probable positive impact on student learning and achievement (Clark, 2010). Meaningful integration of technology is the process of matching the most effective tool with the most effective pedagogy to achieve the learning goals of a particular lesson. Each tool brings different opportunities to the learning environment and involves a different set of skills on the part of teachers and students. Further, each tool can play a unique role in the learning process when used at the appropriate time, under the most suitable learning conditions. Therefore, it is simply the degree to which a particular technology's capabilities are matched with the expected learning outcomes and supported by fitting pedagogy that will determine the impact that technology has on learning and achievement (Clark, 2010).

According to Hamilton (2007), integration is an instructional choice that generally includes collaboration and deliberate planning and always requires a classroom teacher's participation. It cannot be legislated through curriculum guides nor will it happen spontaneously. Integration of technology in the classroom may be a vision of an administrator, a teacher, or a specialist needs to model, encourage, and enable integration; however among those with capabilities to make integration of technology happen, only a classroom teacher can make integration successfully happen in the classroom.

Meaningful technology integration touches ground on motivation and appropriate use of tools to match the learners and pedagogy at hand. The information provided by this research is of value to science teachers working on similar objectives. This also allows science teachers to explore and improve their motivation techniques which may later lead to a deep conceptual understanding of the subject matter (Morales, 2014).

\section{Conceptual Framework}

Upon the review of the different literatures, a conceptual framework has been created and is shown in Figure 1 below.

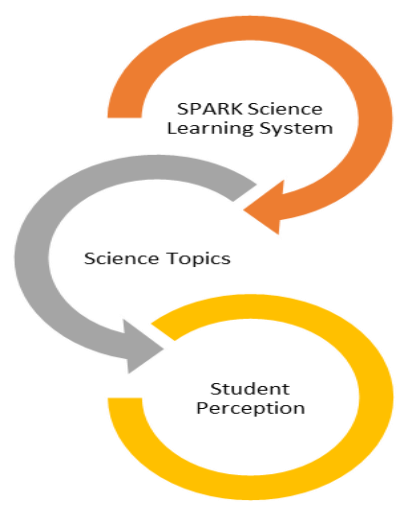

Figure 1. Conceptual Framework

The conceptual framework of the present research as seen in Figure 1shows the three constructs involved in the study. The SPARK Science Learning System has been utilized in teaching certain science concepts and its effect on student perception towards science was determined. As shown in Figure 1, the conceptual framework attempted to explore whether the use of SPARK Science Learning System to perform several experiments could back up the teacher in uplifting the learners' perception in science. This is to find out if the usage of this innovative tool in the selected science topics from the newly adopted $\mathrm{K}$ to 12 Science Curriculum could enhance learners' perception in science. The different literatures unfolded that most of the learners have a negative perception in science. The students considered their negative perception were because of the teachers' way of conveying the science lessons, the teachers' practices in the classrooms and the mastery of the subject matter. This study has addressed those present conflicts in science learning. 


\section{Research Questions}

This research aims to find out if the utilization of SSLS to Science Classes has a significant effect on the learners' perception in science. Specifically, this research aims to answer the following questions:

1. Is there a significant difference between the pre-test and post-test means of the students exposed to SSLS and the conventional method in their perception in science?

2. Is there a significant difference between the post-test means of the students exposed to SSLS and the conventional method of their perception in science?

\section{Methodologies}

\section{Respondents}

The respondents of this study are the 87 learners of Andres Bonifacio Integrated School in the Division of Mandaluyong City. The experimental processes were implemented in two sections out of ten Grade-7 sections of the said school in the School Year 2014-2015.

The SSLS groups are the 44 learners who received the treatment. The treatment was the utilization of SPARK Science Learning System device and sensors on science experiments suggested in the K to 12 science modules. On the other hand, the conventional groups were composed of 43 heterogeneous respondents. They were called the conventional group since they were the learners who had a regular learning instruction which was based on the $\mathrm{K}$ to 12 learning modules.

\section{Setting of the Locale}

This research utilized a quasi-experimental pretest posttest design. The researcher used the topics in the $1^{\text {st }}$ quarter topics in Grade 7. The topics were science investigative processes in the diversity of materials in the environment. The researcher mainly followed the lessons and materials as suggested in the prescribed module of the Grade-7 Enhance Science Curriculum. The instructional processes were implemented for six weeks wherein the teacher-researcher consistently followed the prescribed allotted time for each topic. The topics and the objectives were paralleled in the $\mathrm{K}$ to 12 Curriculum in both groups.

Researcher used two SPARK science learning system and two different passport sensors which were temperature and $\mathrm{pH}$ sensors. These sensors were part of Chemistry packages. Spark lab automatically recorded the numerical values of the time, temperature and $\mathrm{pH}$ levels during the experiments. The allotted time indicated in the SSLS's guidelines, each readymade activity needed to have 150, minutes which is equivalent to 3 days contact with the learners. K-12 curriculum requires 50 -minute period in a day. If the researcher would follow the time in the guidelines of the SSLS, all the lessons in the K-12 curriculum allotted in the $1^{\text {st }}$ grading would not be enough, aside from that, some materials in the laboratory activities were not found in the science laboratory of the school. Readymade activities in the SPARK labs of SSLA were not suited in the $1^{\text {st }}$ Grading lessons of the K-12 Enhance basic curriculum. Thus, the researcher prepared simplified modules for the SSLS group who used the SSLS device and SSLS passport sensors. The principal, the head of the science department and the master teachers were not able to observe the classes. Instead, a weekly checking of lesson plan was made by the head teacher and the assistant to the principal.

Extraneous variables which had affected this study were the absences of the learners, suspension of classes on the $2^{\text {nd }}$ week of the conduct of the study due to typhoon Glenda, weak foundation of their science concepts which were beyond the control of the researcher. Student profiles were not taken prior to the conduct of the study. Students who were re-takers of Science-7 were not a part of respondents.

In terms of the instruction, SSLS group was instructed during the experiments with SPARK science learning system, passport sensors and the other materials suggested in the K-12 Curriculum while the conventional group made use of all the materials listed in the module. The researcher prepared a 
modified module for the SSLS but this adapted the K-12 modules. The only different between the two groups was that the SSLS group had SSLS software and SSLS passport sensors during their experiment whereas the conventional group had none. Conventional group needed to record the result manually while the SSLS group just read the digital data from the SSLS.

After six weeks of instructions with the two classes, a post-test was administered to both groups. Forty three students took the post test in the control group while there were forty four students for the experimental group or a total of eighty seven respondents answered the post test in the survey of science perception. Pre-test and Post test results were gathered from the respondents to determine the learners' perception towards Science.

\section{Instruments}

To determine the perception of students towards learning science, a survey using a questionnaire was administered to the students. The instrument, iKnow My Class Survey, was designed as a formative assessment tool for teachers, giving voice to students' perceptions of various aspects of their individual classes and themselves (Bundick, 2011). The scale of validation of the iKnow My Class Survey used Cronbach's alpha statistics with a reliability test 0.70 .

The research instrument made use of a Likert scale to assess the student's agreement or disagreement with the statement to find out the students perception in science. The choices of the respondents range from 1-5 where 5 shows the respondent strongly agrees and 1 if respondent strongly disagree for positive statement, while it is reversely coded for the negative statements.

The choices of the respondents in the survey questionnaire have corresponding scores. Positive and negative statements in the choices were scored 5-1 respectively. The ratings of the students' responses in perception questions were computed to determine the over-all perception of the students towards science. Below are the arbitrary points to be used in interpreting the over-all rating of learners' perception (Soliven, 2004).

\begin{tabular}{ll} 
Rating & Perception Level \\
\hline $4.2-5$ & Very Positive \\
$3.5-4.1$ & Positive \\
$2.4-3.4$ & Fairly Positive \\
$1.6-2.3$ & Negative \\
$1-1.59$ & Very Negative
\end{tabular}

\section{Results}

Statistical treatment assisted the researcher in finding out whether significant difference exists between the pre-test mean and posttest means on the perception of the control and experimental groups. The researcher employed independent sample mean t-test to compare the posttest of the SSLS group and the conventional group while paired samples mean t-test was used to compare their pretest and posttest mean scores.

Initially, the learners' test scores in their pre-test had undergone test of normality to find out whether they are normally distributed to determine what statistical treatment should be employed. It employed Shapiro-Wilk Test for normality at 0.05 level of significance.

Table 1: Shapiro Wilk Test of Normality

\begin{tabular}{|c|c|l|c|c|}
\hline Variable & Group & Test & p-value & Interpretation \\
\hline $\begin{array}{c}\text { Science } \\
\text { Perception }\end{array}$ & Conventional Group & Pretest & 0.263 & Normal \\
\cline { 2 - 5 } & SLSS Group & Pretest & 0.086 & Normal \\
\hline
\end{tabular}

Table 1 shows that the normality for the distribution of the data varies. Shapiro Wilk-test analysis revealed that the pre-test scores of both control and experimental groups in their perception in science and integrated science process skills are normally distributed. 
The primary goal of this study is to find out the effect of usage of SPARK Science Learning System on students' perception. To determine if there is a significant gain in learners' perception in Science, statistical comparison of the pre-test and post-test of the participants exposed to SSLS and those who were under the conventional method on their perception in Science through paired sample t-test is presented in the table below.

Table 2: T-test comparison in the Pre-test and Posttest Scores in Science Perception

\begin{tabular}{|c|c|c|c|c|c|c|}
\hline Group & Test & N & Mean & t-test & p-value & Interpretation \\
\hline \multirow{2}{*}{ Conventional } & Pre-Test & 43 & 204 & -2.43 & 0.019 & Significant \\
\cline { 2 - 4 } & Posttest & 43 & 214.05 & & & \\
\hline \multirow{2}{*}{ SSLS } & Pre-Test & 44 & 208.16 & -3.53 & 0.001 & Significant \\
\cline { 2 - 4 } & Posttest & 44 & 221.25 & & & \\
\hline
\end{tabular}

Table 2 shows that the participants in the SSLS group had a higher perception in their posttest as compared to the pre-test after the utilization of the SPARK Science learning System. The difference in the pre-test mean and the posttest mean was statistically significant with a p-value less than 0.05 (pvalue $=0.001<0.05$ ). Similarly, participants in the conventional group had a better perception too in the posttest as compared to the pre-test after the used of the prescribed Grade-7 modules in their perception in Science. The difference in the pre-test mean and the post-test mean was statistically significant with a p-value of less than $0.05(\mathrm{p}$-value $=0.019<0.05)$. The SSLS group that utilized SPARK Science Learning System has higher mean difference in their perception in science than the conventional group. The pre-test and posttest mean difference of the control group is 10.047 while experimental group is 13.09 ( $\mathrm{Md}=10.07<13.09)$. However, results show significant gains in both groups in the students' perception in Science. This implies that the utilization of both SPARK Science Learning System and the K-12 Science modules in teaching Science Investigative Processes in the diversity of materials in the environment could be an avenue in improving learners' perception in Science.

The present result seems to respond on the study conducted by Bernardo, et.al (2008) whom suggested that students perceive that their teachers' instructional practices are oriented towards helping them learn but that these practices do not involve enough of inquiry-oriented activities and do not provide enough support or encouragement for self-directed and effortful learning. Utilization of SPARK Science Learning System as well as the modules prescribed in the K-12 Curriculum were bunches of activities to encourage learners to perform different tasks and hold on the idea of learning by doing.

The rating of the students' responses in perception questions was computed to determine the over-all weighted mean in the learners' perception in science. Arbitrary points were used in interpreting or determining the level of perception of as shown in the table below.

Table 3: Pre-test and posttest over-all mean score of the control and the experimental groups and interpretation of level of the learners' perception

\begin{tabular}{|c|c|c|c|}
\hline Group & Test & $\begin{array}{c}\text { Over-All Weighted } \\
\text { Mean }\end{array}$ & Level of Perception \\
\hline \multirow{2}{*}{ Control } & Pre-Test & 4.07 & Positive \\
\cline { 2 - 4 } & Post-Test & 4.28 & Very Positive \\
\hline \multirow{2}{*}{ SSLS } & Pre-Test & 4.16 & Positive \\
\cline { 2 - 4 } & Post-Test & 4.4 & Very Positive \\
\hline
\end{tabular}

Table 3 shows the comparison of the participants pre-test over-all weighted and posttest over-all weighted means on the learners' perception in science. The result shows that there is an increase in the perception level in both groups. The pre-test over-all weighted mean in both groups show that the learners have positive perception prior to the instructional process. The posttest over-all weighted mean indicates that both groups have a very positive level of perception in science. It could be deduced that both groups changed their level of perception in science after implementation of the two 
learning pedagogies. This implies that both learning pedagogies have the ability to increase students' level of perception in science. However, it was observed that the SSLS group has a higher weighted mean score than the conventional group.

The result of this study agrees with (Montebon, 2014) that the learners have positive perception in the K-12 Science Curriculum. As shown in table 3, the pre-test of the conventional and the experimental group revealed that the participants have positive perception towards the implementation of the K-12 Science Curriculum prior to the implementation of the instruction. Although learners have already manifested a positive perception towards science due to the newly implemented curriculum, the posttest mean score in their perception in science were significantly different. This significant gain made their positive perception become very positive. This change signifies that after the implementation of both learning pedagogies, SSLS group that used SSLS and the conventional group that used the prescribed modules in Science can be avenue to uplift the learners' perception in science.

On the contrary, this result disagrees with the findings of Jenkins and Pell (2006) from the ROSE project on the science perspective of students in England. These are largely concurrent with those of school students from industrialized nations globally. Most boys but, in particular, girls prefer other subjects to science. Furthermore, the study of Bevins and Brodie (2005), a study in England on secondary school students' perceptions of science and engineering and found out that students do not recognize the specific identities and importance of science regarding their role in society as much as they do with politics. Seymour and Hewitte (1997) revealed that many informative perceptions of students, such as the perception that science teachers dislike their students and do not have the motivation to teach effectively. The students interviewed also perceived many features of ineffective teaching in science such as the lack of fit between the materials used in class and the tests and assignments, the use of grading practices that do not reflect actual student learning, an overemphasis on memorization instead of conceptual understanding and establishing conceptual connections, among many others. Their study of students' perception revealed notions of good teaching in science classes, such as encouraging discussion, and valuing the sense of discovering things together, and respecting students

Negative perception in science among learners in the previous studies was observed in different countries. Notice that these results could have been different in terms of perspectives of participants depending on the setting. The adaption of the K-12 Science curriculum might have been a factor that changed the learners' perception in science.

To explicitly detail whether specific component in learners' perception in science has truly improved, the pre-test means and posttest means comparison of the eight components of the learners' perception in science of the control group is shown in Table 4 below.

Table 4. T-test Comparison of the Eight Components in Science Perception of the Conventional group

\begin{tabular}{|l|r|r|r|r|l|}
\hline \multicolumn{1}{|c|}{ Skill } & \multicolumn{1}{|c|}{ Pre-test } & Posttest & \multicolumn{1}{c|}{ t-value } & \multicolumn{1}{c|}{ p-value } & \multicolumn{1}{|c|}{ Interpretation } \\
\hline Meaningful Engagement & 2.52 & 24.1 & -1.3 & 0.200 & not significant \\
\hline Relevance & 3.03 & 31.14 & -1.18 & 0.24 & not significant \\
\hline Relationship & 37.07 & 39.35 & -2.54 & 0.015 & significant \\
\hline Class Efficacy & 48.98 & 51.91 & -1.52 & 0.076 & not significant \\
\hline $\begin{array}{l}\text { Cooperative Learning } \\
\text { Environment }\end{array}$ & 20.02 & 21.4 & -2.23 & 0.031 & significant \\
\hline Critical Thinking & 36.19 & 39.6 & -3.27 & 0.002 & significant \\
\hline Positive Pedagogy & 4.25 & 4.23 & 0.113 & 0.898 & not significant \\
\hline Discipline Problem & 1.84 & 2.37 & -1.9 & 0.064 & not significant \\
\hline
\end{tabular}

Table 4 shows that after the implementation of the instructional processes, the control group increased the critical thinking and class efficacy of science perception respectively. Most of the eight factors in science perception had increased after the implementation of the instructional process. T-test revealed that only the three components in science perception had increased significantly. The differences in 
the pre-test mean and the posttest means of three components were statistically significant. These are as follows: in relationship with a p-value of 0.015 less than 0.05 ( $\mathrm{p}$-value $=0.015<0.05)$, in cooperative learning environment, the $\mathrm{p}$-value of 0.031 less than 0.05 (p-value $=0.031<0.05)$ and critical thinking with the $p$-value of 0.002 less than 0.05 (p-value $=0.002<0.005$ ) is also less than and critical thinking. This implies that usage of the prescribed modules in Science can uplift such factors. These three components are important factors in learning science. Relationship is the building up a positive relationship between the learners and the teachers brings a good camaraderie which can result to positive learning outcome. Positive relationship among learners could lead to cooperative learning of the students. Learner's perception in critical thinking improved too, thus this implies that the learners, developed their science-inquiry skill, which is the aim of the SSLS.

However, it could be observed that after the posttest, the engagement of the learners in the conventional group has a decrease of 1.1. The occurrence may have happened because certain learners were absent and there were many tasks to do during the instructional process. When they came back for school, they had a lot of activities to catch up. They were also tasked to perform several experiments which they are not used to prior to the instructional process. In an interview, a student from the conventional group honestly replied, " $[w]$ e did not usually perform science experiments in the past. We experienced difficulty and confusion in the different tasks but we believed, experiments are needed in science classes because these will help us learn more." Such difficulty of students agrees with de Frondeville (2009) and Weiss and Pasley (2004) ideas that student motivation and adaptability towards technology in the classroom takes time and is affected by different factors: exposure time to the technology, engagability of activities provided, and the competence of students for the technology.

To explicitly detail the specific components if learners' perception in science has truly improved, the pre-test means and posttest means comparison eight of the components of the SSLS is shown in the table 5.

Table 5: T-test Comparison of the Eight Components of Science Perception of the Pre-test and Posttest of the SSLS Group

\begin{tabular}{|l|r|r|r|r|l|}
\hline \multicolumn{1}{|c|}{ Skill } & \multicolumn{1}{c|}{ Pre-Test } & \multicolumn{1}{c|}{ Post Test } & \multicolumn{1}{c|}{ t-test } & \multicolumn{1}{c|}{ P-value } & \multicolumn{1}{c|}{ Interpretation } \\
\hline Meaningful Engagement & 25.2 & 25.5 & -2.31 & 0.822 & not significant \\
\hline Relevance & 29.57 & 31.23 & -2.39 & 0.021 & significant \\
\hline Relationship & 37.97 & 40.86 & -3.39 & .002 & significant \\
\hline Class Efficacy & 48.98 & 51.91 & -3.55 & .001 & significant \\
\hline $\begin{array}{l}\text { Cooperative Learning } \\
\text { Environment }\end{array}$ & 20.02 & 21.4 & -1.25 & 0.218 & not significant \\
\hline Critical Thinking & 36.19 & 39.6 & -3.27 & 0.002 & significant \\
\hline Positive Pedagogy & 4.25 & 4.23 & -0.91 & 0.368 & not significant \\
\hline Discipline Problem & 1.84 & 2.37 & -1.86 & 0.07 & not significant \\
\hline
\end{tabular}

Table 6 shows that after the post test, the experimental group obtained the highest increment in class efficacy and critical thinking in science perception. The comparison of posttest and pre-test of the SSLS group revealed significant gain in the four components in learners' perception in science which are relevance, $(p$-value $=0.021<0.05)$ relationship (p-value $=002<0.05)$, class efficacy ( $p$ value $=001<0.05)$ and critical thinking ( $\mathrm{p}$-value $=0.002<0.05$ ). This result implies that usage of SSLS in science class could further improve such components. This shows that SPARK has the ability to improve the following: teachers and learners' application of the content and information how this science content applies to the student's everyday lives, the trust and the mutual respect between the students and the teachers, the assurance of the teacher that the students are able to be themselves, ease in making inquiries about the content hesitation when asking for support in their own learning.

\section{Comparison of Post-tests Scores in Perception}

Problem number 2 aimed to find out if there is a significant difference between the post-test means of the students exposed to SSLS with those who were under the conventional method in their science 
perception. An independent sample t-test was employed to determine if there is a significant difference in learners' perception in science. The statistical comparison of post-test of the participants exposed to SSLS and those who were under the conventional method on their perception in science is presented in the table below.

Table 6: T-test comparison between the post-test mean scores of the control and the experimental groups on their Science Perception

\begin{tabular}{|c|c|c|c|l|l|l|l|}
\hline Variable & Group & N & Mean & $\begin{array}{l}\text { Mean } \\
\text { Difference }\end{array}$ & t-value & p-value & Interpretation \\
\hline $\begin{array}{c}\text { Science } \\
\text { Perception }\end{array}$ & Conventional & 43 & 214.05 & 7.2 & -2.22 & 0.029 & Significant \\
\cline { 2 - 7 } & SSLS & 44 & 221.25 & & & \\
\hline
\end{tabular}

Table 7 shows the over-all post-test mean scores of the two independent samples. The conventional group has a post-test mean score of 214.05 while the SSLS group has a mean score of 221.25. These mean scores have a mean difference of 7.2 which gain a p-value of 0.029 less than 0.05 level of significance $(\mathrm{p}$-value $=0.029<0.05)$. Such difference suggested that there is a significant difference on the post-test mean scores in the science perception between the conventional and the SSLS groups. This implies that the integration of SSLS has a positive effect on the learners' science perception better than the conventional group. This study also revealed that after the implementation of the experimental process, the group which received the integration of SSLS had higher science perception than the control group which had the traditional method of teaching under the K-12 curriculum. This suggests that SSLS can elevate the perception of learners in science.

Present study revealed that utilization of SPARK Science Learning System improved learners' perception in science. Previous studies also disclosed that perception and achievement are correlated, that supports why ISPS of the learners improved as well.

This study agrees on the study of Kumar and Sampath (2010), the main role of perception in learning is to speed up the learning process and recall. Exposure to stimulus develops the interest and conscious knowledge of a person which enables better understanding and learning of the person about a specific subject. This denotes that as the perception of learners improve; the more motivated they will be in learning the subject thus, they will perform better as well.

To explicitly detail which specific component of the learners' perception in science has significant difference between the posttest means of the control and the SSLS groups, statistical comparison of the posttest means of the participants on their perception in science through independent sample means t-test was made as presented in the table below.

Table 7. Posttest Comparison of the Component of the Conventional and SSLS Groups in Science Perception

\begin{tabular}{|l|c|c|c|c|c|}
\hline \multicolumn{1}{|c|}{ Skill } & Conventional & SSLS & t-value & p-value & Interpretation \\
\hline Meaningful Engagement & 24.1 & 25.5 & -2.00 & 0.049 & significant \\
\hline Relevance & 31.14 & 31.23 & -0.143 & 0.866 & not significant \\
\hline Relationship & 39.35 & 40.86 & -1.95 & 0.037 & significant \\
\hline Class Efficacy & 51.91 & 54.09 & -1.43 & 0.158 & not significant \\
\hline $\begin{array}{l}\text { Cooperative Learning } \\
\text { Environment }\end{array}$ & 21.4 & 21.68 & 0.472 & 0.638 & not significant \\
\hline Critical Thinking & 39.6 & 40.68 & -1.28 & 0.206 & not significant \\
\hline Positive Pedagogy & 4.23 & 4.18 & 0.32 & 0.749 & not significant \\
\hline Discipline Problem & 2.37 & 2.86 & -1.57 & 0.12 & not significant \\
\hline
\end{tabular}

Table 8 shows the comparison of the mean scores and their mean differences between the conventional and the SSLS groups. It statistically reveals that utilization of SSLS has improved in terms of meaningful engagement with a p-value of 0.049 less than 0.05 level of significance (pvalue $=0.049<0.05)$ and relationship with a $\mathrm{p}$-value of 0.037 less than 0.05 level of significance $(\mathrm{p}$ value $=0.037<0.05)$. This reveals that most of the mean scores of the experimental group were higher than the control group. Class efficacy has the greatest mean difference though difference was not 
significant. Since the difference on the over-all posttest mean scores of the control and the experimental group were statistically significant, it could imply that, utilization of SSLS has a better effect on the over-all science perception of the learners in the experimental group. In the eight components, it specifically unfolded that the SSLS group has a better improvement in learners' engagement and relationship.

This implies that SSLS improved the engagement of learners to learn the concepts through experiments and built up a better student-student and teacher-student relationships.

\section{Conclusions}

The present research investigates primarily the perception of students of their science lessons when technology in the form of SSLS was used in their classes. The pre and post test scores of students' responses on the iKnow My Class Survey revealed a significant difference $(t=-2.11$ at 0.0 sig.). It means that students' perceptions of their classes were positive upon using SSLS in their classes.

Results of the study agrees with the findings of different researchers (Valdez, 2005; Chingos \& Whitehurst, 2012; Aurentz, Kerns \& Shibley, 2011; Morales, 2014). According to Valdez (2005), technology based learning tool is needed to achieve statistically significant effects. Thus, the use of SSLS to science investigative lessons support that educators must adapt to the modernizing education setting by infusing technology in their classroom strategies. The results of this study also agree with Chingos and Whitehurst (2012) whom revealed that there was strong evidence that the choice of instructional materials has large effects on student learning. Contrary to common practice of educational institutions to wrongly or blindly choose instructional materials without evaluation most of the time, results of the present research affirms the schools' effort to properly evaluate the impact of SSLS on the learners performances through this study.

To assist students as they learn science under the $\mathrm{K}$ to 12 program is the underpinning principle of the researchers upon the conduct of this study. Consequently, research results revealed that SSLS improved their view of their science classes; Aurentz, Kerns and Shibley (2011) said that inclusion of modern instrumentation indicated a positive change in students' perception in scientific ideas.

Bernardo (2004) suggest that classrooms in the Philippines should anchor more on the constructivist philosophy. In the present research, constructivism has been an evident philosophy that have been observed in the classroom as student learn science with the use of SSLS; for SSLS may allowed learners to connect lessons with prior knowledge and investigate new concepts through hands on experiences that lead them to develop new knowledge.

Lastly, the results of the research affirms that of Morales (2014): SPARK Science Learning System is an effective technology to be used in science classes for it enables students to improve their innovation skills, develop their creativity, use critical thinking, enhance their communication skills, and collaborate with their peers and teacher. That said, the present research posits that SPARK Science Learning System can help assist the K to 12 program to achieve its goals of developing a scientific literate citizen.

\section{References}

[1] Auditor, E. \& Roleda L. (2014). The WebQuest: Its impact on students' critical thinking,performance, and perceptions in physics. International Journal of Research Studies in Educational Technology, 3(1), 3-21.

[2] Aurentz, D. \& Kerns, L. (2011). Improving Student Perceptionsof Science Through the Use of State-of-the-Art Instrumentation. Journal of College Science Teaching, 40(6).

[3] Bernardo, A. B. I. (2004). Constructivism, curriculum and the challenges in transforming science education in the Philippines. Learning Edge, 4, 1-33.

[4] Bernardo, A., Limhap, A., Prudente, M., \& Roleda, L. (2008). Students' Perceptions of Science Classes in the Philippines. Asia Pacific Education Review, 9(3), 285-295. 
[5] Bevins, S., Brodie, M., \& Brodie, F., (2005). A study of UK secondary school students' perceptions of Science. Retrieve December 12, 2014 from http://shura.shu.ac.uk/956/1/fulltext.pdf

[6] Bundick, M. J. (2011). Scale Validation of the I know my Class Survey.

[7] Cabansag, M.G. (2014). Impact Statements on the K-12 Science Program in the Enhanced Basic Education Curriculum in Provincial Schools. Journal of Arts, Science \& Commerce, 5 (2). 29-39

[8] Centra, J. \& Gaubatz, N., (2005). Perceptions of Learning and Instructional Effectiveness in College Courses. Retrieved from https://www.ets.org. on December 15, 2014

[9] Chingos, M. M. \& Whitehurst R. G. (2012). Choosing Blindly Instructional Materials, Teacher Effectiveness, and the Common Core. Retrieve from https://www.brookings.edu/wp on November 20, 2014

[10] Clark, J. (2010). Best Practices Research Summary. Sun Associates. Retrieved November 1, 2012 from www.sun-associates.com

[11] de Frondeville, T (2009) How to Keep Kids Engaged in Class, Edutopia. Retrieved from http://www.edutopia.org on January 2015

[12] Department of Education (2013). K-12 Curriculum Guide in Science. Retrieved Aug. 18, 2013 from http://www.deped.gov.ph/sites/default/files/page/2014/Final\%20Science\%20CG\%20310\%2005.08.2014.pdf

[13] Enhanced Basic Education Act of 2013, Pub. L. No. RA 10533 (2012). Retrieved from http://www.officialgazette.gov.ph/2013/05/15/republic-act-no-10533/

[14] Fonseco, J. M., Conboy, J. E., (2006). Secondary student perceptions of factors affecting failure in Science. Eurasia Journal of Mathematics, Science and Technology Education, 2(2), 82-95.

[15] Hamilton, B. (2007). Integrating technology in the primary grades. International Society for Technology in Education. Retrieved July 9, 2014 from http://www.iste.org/images/excerpts/ITSELE-excerpt.pdf

[16] Hançer, A. H. \& Tuzemen, A. T., (2008). A Research on the Effects of Computer Assisted Science Teaching. World Applied Sciences Journal, pp. 199-205.

Institute for Student Aspirations.Retrieved from www.qisa.org on February 9, 2014

[17] Jenkins, E. W. \& Pell, R. G., (2006). The Relevance of Science Education Project (ROSE) in England: A Summary of Findings. Centre for Studies in Science and Mathematics Education, University of Leeds, Leeds LS2 9JT, UK

[18] Kardash, C. A., \& Wallace, M. L. (2001). The perception of science classes survey: What undergraduate science reform efforts need to address. Journal of Educational Psychology, 93, 199-210.

[19] Kumar, G.T., \& Sampath, B.T., (2010). Perception and usage of e-resources and the internet by Indian academic. The Electronic Library, 28(1), 137 - 156,

[20] Marzano, R. J. ( 2006). Different kind of classroom. Retrieved on February 9, 2015 at http://www.ted.com/conversations/14518/perception is an important asp.html

[21] Montebon, D. R., (2014). "K12 Science Program in the Philippines: Student Perception on its Implementation," International Journal of Education and Research, 2(12), 153-164.

[22] Morales, M. P., (2014). Influential Factors in Modelling SPARK Science Learning System. International Journal of Learning, Teaching and Educational Research, 4(1)., 36-50

[23] Psych Info Database Record, (2012). Retrieved from http://www.apa.org/pubs/databases/psycinfo/

[24] Salgut, B., (2007). The effects of computer assisted instruction along with internet for 5th grade primary school students' acquisition in science and technology lessons light and voice unit. Unpublished Master Dissertation, Çukurova University, Turkey.

[25] Seymour, E., \& Hewitte, N. M., (1997). Talking about leaving: Why undergraduates leave the sciences. Boulder, CO: Westview Press

[26] Tuga, B., \& Montebon, D. R. (2017). The Ethnography of K to 12 Classrooms in the Philippines. Unpublished manuscript, Manila.

[27] Valdez, G., (2005). Critical issue: Technology: A catalyst for teaching and learning in the classroom. North Central Regional Educational Laboratory. Retrieved, Feb. 9, 2014 from http://www.edu2.georgetowncollege.edu 
[28] Weiss, I.R. \& Pasley, J.D., (2004). Improving Achievement in Math and Science What Is HighQuality Instruction? 61(5), 24-28.

[29] Yakar, H., (2005). The effects of computer assisted teaching on student's success in teaching Newton's movement laws. Yuksek Lisans Tezi, Pamukkale, Institute of Sciences, Denizli, Turkey

\section{Authors}

Maribel D. Ganeb, PhD Student, Philippine Normal University, email:waribelganeb@gmail.com

Darryl Roy T. Montebon, Assistant Professor III, Institute of Teaching and Learning, Philippine Normal University, montebon.drt@ pnu.edu.ph 
